\title{
25 Research Suare \\ Incidence and Prevalence of HIV in Sub-Saharan Africa: Focus on Cameroon, Ethiopia, Ghana, and Zambia
}

Ebenezer, Akuoko ( $\nabla$ akuoko.eb@students.dvfu.ru )

School of Biomedicine, Far Eastern Federal University

Eliud, Sandabunga

School of Biomedicine, Far Eastern Federal University

Eunice, Akuoko

Bibiani Government Hospital, Ghana

Kenneth, Baga Sabogu

Ghana AIDS Commission, WA

\section{Research Article}

Keywords: HIV/AIDS, prevalence, incidence, Sub-Saharan Africa, people living with HIV, ART, ARV, Motherto-child transmission

Posted Date: April 23rd, 2021

DOl: https://doi.org/10.21203/rs.3.rs-453650/v1

License: (9) This work is licensed under a Creative Commons Attribution 4.0 International License. Read Full License 


\section{Abstract}

More than one-third of people living with HIV/AIDS live in the Sub-Sharan Africa region. The study focused on Cameroon, Ethiopia, Ghana, and Zambia to give a general overview of the situation in the region. 2019 data by UNAIDS were assessed and compared with the 2018 data. The results revealed a disproportionate burden of the disease among women aged 15 years and above, as compared to men of the same ages and children below 15 years. Also, it was revealed that ARV services among pregnant women are effective in reducing the number of new infections among newborns. It is this important that in the fight against the epidemic in the region, governments and their development partners should give much attention to women.

\section{Introduction}

Following the launch of the Millennium Development Goals (MDGs), efforts in the fight against HIV/AIDS have intensified (Deribew et al., 2019). The high level of attention given to this health problem was affirmed through its inclusion in the Global Fund, which was established in 2002. Subsequently, contributions by multilateral, bilateral, foundations, and non-governmental organizations towards this fight from 2000 to 2011 amounted to US\$51.6 billion (Murray \& et.al, 2014). These efforts were aimed at achieving the MDG 6A, which sought to halt the spread of the disease by 2015 and then begin to reverse it, and 6B, which sought to by 2010, achieve universal access to treatment for HIV/AIDS for all those who needed it (WHO, 2014).

Consequently, over the years, several countries made significant successes in combatting HIV, although some countries continued to struggle. For instance, in 2013, 26 countries reported that they had successfully reduced the incidence of HIV by 50\%. However, in 2015, Prendergast, Essajee, \& Penazzato reported that in 22 countries, of which 21 are in the sub-Saharan Africa region, urgent steps were required to address the spread of HIV as $90 \%$ of new infections occurred in those countries (Prendergast, Essajee, \& Penazzato, 2015).

Like the MDGs, the combat against HIV is an important part of the Sustainable Development Goals (SDGs). Integrated into a broader health goal to ensure healthy lives and promote well-being for all ages, goal 3 of the SDGs has a specific target to end the epidemic of HIV by 2030 (Fowkes et al., 2016). Subsequently, in 2014, the UNAIDS launched a "Fast-Track" strategy on HIV/AIDS, which ran from 2014 to the end of 2020. The strategy sought to reduce new HIV infections and deaths related to AIDS by $90 \%$ by 2030, using 2010 as a baseline. It aimed at ending AIDS as a threat by 2030 by ensuring a reduction in annual incidence to fewer than 500,000 by 2020 and fewer than 200,000 by 2030 (Avert, 2018).

Despite these efforts, including great advancements in antiretroviral therapy (ART), over 39 million AIDSrelated deaths are recorded annually across the globe (Pandey \& Galvani, 2019). An estimated 37.9 million people were living with HIV in 2018 and about $21 \%$ of them do not know that they have the virus 
(Avert, 2020). Thus, the disease continues to be a major public health concern, especially in the SubSaharan Africa region.

Although only $12 \%$ of the global population live in the Sub-Saharan Africa region, (Kharsany \& Karim, 2016), it is the most affected among all the regions of the WHO and represents two-thirds of all global infections. According to the WHO, 25.7 million people in the region were living with HIV in 2018, with 1.1 million new infections (WHO, 2020).

The burden of HIV on the African continent, especially among countries in the Sub-Sharan African Region has drawn a lot of attention from several stakeholders like the international communities, Non-

governmental organizations, and researchers. The link between poverty and the spread of the disease has been widely discussed. Thus, efforts to combat the epidemic in the continent have been aligned with the reduction and or elimination of extreme poverty among inhabitants of the region. There have thus been several calls on governments of countries in the region to prioritize the HIV fight. Through the collaborations of several African governments and their development partners, some efforts have been made to address the challenge.

\section{Cameroon}

In 1986, the government of Cameroon established the National AIDS Control Committee (NACC) to coordinate AIDS programs in the country. A year after, the Global Plan on AIDS was introduced by the WHO. Subsequently, a 5-year strategic plan for the country to cover 2000 to 2005 was implemented to guide prevention programs. From 2006 to 2010, the country was guided by its second strategic plan which focused on six aspects: Universal access to HIV prevention in targeted groups; Universal access to treatment for adults and children living with HIV; Protection and support to AIDS orphans and vulnerable children; Involvement of all stakeholders in the fight against HIV and AIDS; Epidemiological surveillance and research promotion as well as the Reinforcement and coordination and management of the program, partnerships and the monitoring and evaluation of its implementation (Mbanya, Sama, \& Tchounwou, 2008). A recent strategic plan by the UNICEF Cameroon Country Programme for 2018 to 2020, sought to ensure equitable and sustainable access to HIV/AIDS prevention, care, and treatment services among women, children, and adolescents (UNICEF, 2020).

Notwithstanding several efforts made to combat the disease in the country, Cameroon is among the Central African countries most affected by HIV/AIDS, with an estimated prevalence rate of $4.3 \%$. It is among the 10 countries that make up $75 \%$ of all pediatric HIV infections. The Mother-to-child transmission rate is high at $14 \%$, and the antiretroviral treatment rate among children and adolescents remains extremely low (13\%). Due to child marriage, sexual and physical violence, adolescents in the country remain vulnerable to infection (UNICEF, 2020).

\section{Ethiopia}


Attempts to combat HIV in Ethiopia, located in East Africa date to the 1980s. In 1985, a National Task Force on HIV was established, following which two medium-term prevention and control plans were designed and implemented between 1987 and 1996. Two years later, a comprehensive HIV/AIDS policy was adopted. Moreover, a five-year strategic plan was adopted through the establishment of the National AIDS Prevention and Control Council. Other interventions include the Strategic Framework for the National Response to HIV/AIDS in 2001; Social Mobilization Strategy on HIV/AIDS and National Multisectoral Strategy 2004-2000 (Kloos \& Mariam, 2000; WHO, 2005b). Ethiopia aligned itself with the Fast-Track targets of the UNAIDS through the development of the Ethiopian Health Sector Transformation Plan (HSTP) to reduce the incidence of HIV among adults by $60 \%$ and record zero new HIV infections among children 2020 from the 2010 baseline (Mirkuzie et al., 2021).

Through the adoption of several positive policies, strategies, and legal frameworks to combat HIV/AIDS, Ethiopia has achieved tremendous success in controlling the disease over the past decade, putting the country on the path of controlling the epidemic. However, the remaining gaps, which are due to serious structural and economic barriers to the implementation of interventions need attention (DCA, n.d.; USAID, 2020).

\section{Ghana}

In 1985, the National Advisory Commission on AIDS (NACA) was established as the first national HIV/AIDS response to advise the government on HIV/ AIDS issues in the West African country. Two years later, the National AIDS Control Programme (NACP) was established to implement and coordinate HIV/AIDS-related programs. Subsequently, short, and medium-term plans were developed, including a National HIV/AIDS and STI Policy. The National HIV/AIDS Strategic Framework 2001-2005 for Ghana was developed in recognition of the disease as one that required holistic, multi-sectoral, and multidisciplinary response to confront (Rawlings, 2001). From the experiences from the Strategic Framework 2001-2005, the National Strategic Framework 2006-2010 was developed to recognize the epidemic as a socio-developmental challenge (Ghana AIDS Commission, 2010). In 2016, Act 2016, Act 938 of Parliament established the Ghana AIDS Commission, under the Chairmanship of the President of the Republic of Ghana, to formulate policy on the HIV and AIDS epidemic and to direct and coordinate activities in response to HIV and AIDS (Ghana AIDS Commission, 2019).

\section{Zambia}

HIV and AIDS is a major developmental challenge for Zambia, which has one of the highest HIV prevalence rates in Southern Africa and the world (National Aids Council, 2014). The National AIDS Surveillance Committee and the National AIDS Prevention and Control Programme were established in Zambia in 1986. A year after, a short-term emergency plan was established to ensure a safe blood supply, after which two medium-term plans were implemented. In 2002, the National HIV/AIDS/STI/TB Council (NAC) was established to coordinate the national multisectoral response, leading to the development of the National HIV/AIDS/STI/TB Intervention Strategic Plan 2002-2005. Moreover, a national 
implementation plan for scaling up antiretroviral therapy in the country was developed to cover 2004 and 2005 (WHO, 2005a).

In 2017, the Government of Zambia adopted two strategies, the National AIDS Strategic Framework (NASF) 2017-2021 and the Adolescent Health Strategy 2017-2021. The HIV Strategic Framework prioritizes global treatment and prevention for children, mothers, and adolescents. The Adolescent Strategy emphasizes sexual reproductive health and HIV, with the prevention of teenage pregnancy, scaling up HIV testing, and condom programming, among priorities (UNICEF Zambia, n.d.).

\section{The $90-90-90$ targets}

In 2016, the United Nations General Assembly's Political Declaration on Ending AIDS committed countries to the 90-90-90 targets. These targets were aimed at making accessible, HIV testing and treatment to most people living with HIV by the end of 2020 . The targets envisioned that, by $2020,90 \%$ of people living with HIV would have known their HIV status, $90 \%$ of people who knew their HIV-positive status would have accessed treatment and $90 \%$ of people on treatment would have suppressed viral loads. These targets have made remarkable gains, although several countries were far from meeting the targets. Globally at the end of $2019,81 \%$ of people living with HIV knew their HIV status, and more than two-thirds $(67 \%)$ were on antiretroviral therapy, recording a more than tripled proportion since 2010. (UNAIDS, 2020).

\section{UNAIDS AIDS Strategy, 2021-2026}

A global strategy for AIDS is being developed by the UNAIDS for 2021 to 2026 . The strategy seeks to reduce the number of global new HIV infections to 370,000 , and the number of deaths due to AIDS-related illnesses to 250,000 by 2025 (UNAIDS, 2021).

\section{Methods And Materials}

A descriptive study design was used in this study. A stratified sampling technique was used to classify countries in the Sub-Saharan Africa region, according to the location; Western, Southern, Eastern, and Central. A simple random sampling technique was then used to select one country from each stratum. Most current (2019) quantitative data were collected from the website of the UNAIDS. The results were analyzed statistically using the Statistical Package for Social Sciences version 11.0 software and Microsoft Excel. The results are presented in charts.

\section{Results}

Please refer to the figures section for the results.

\section{Discussions}




\section{Cameroon}

In 2019, about 511,000 people were living with HIV in Cameroon, representing a 5\% decrease from the 540,000 recorded in 2018. Besides, the number of new cases of HIV recorded in 2019 was $26 \%$ less than the number recorded in 2018 . Whiles $63 \%$ of people living with the disease in 2019 were women, $31 \%$ were men. Moreover, the prevalence rate among women was $4.2 \%$ as against the $2 \%$ recorded among men. There were also $25 \%$ more new cases among women than were recorded among men. These observations are indications that women in Cameroon experience more than half of the burden of HIV/AIDS in the country. This is a worrying situation as, in the summary of their report, Awuba \& Macassa, 2008 had similar observations and ascribed this disparity to the biological vulnerability, sociocultural as well as economic factors among women.

AIDS-related deaths recorded in the country in 2019 decreased by about 22\% from the number recorded in the previous year. This decrement may be due to the $10 \%$ increase in ART coverage among people living with HIV in 2019 as compared to 2018. However, the proportion of HIV-infected women who received ARV dropped from $80 \%$ in 2018 to $73 \%$ in 2019 . As a result, while 4200 new HIV infections among newborns were prevented in 2018, 3200 were prevented in 2019. The proportion of HIV-infected people who knew their status in 2019 was $79 \%, 5 \%$ more than the proportion recorded in 2018 . These put the country far from achieving the $90-90-90$ targets of the UNAIDS for 2020.

\section{Ethiopia}

In 2019, 664,000 adults and children were living with HIV in Ethiopia, a 4\% reduction in the number recorded in 2018. Deaths due to AIDS in the country increased by about $5 \%$ in 2019 from the number recorded in 2018. Also, the number of new cases reduced by $36 \%$ from the 23,000 recorded in 2019 . $3 \%$ more people who were infected with HIV in 2019 knew their status than the proportion recorded in 2018. Women in Ethiopia suffer the most burden of the disease. This is because they represented about $59 \%$ of all people living with HIV. Moreover, the proportion of women among all new cases recorded in the same year was $49 \%$. The proportion of new cases among children was unacceptable. They represented about $22 \%$ of all cases recorded. Thus, together, children and women represented $78 \%$ of new cases recorded. The disproportionate HIV/AIDS burden among women and children has been recognized by other researchers such as Girum et al., (2018). Concluding their report, they contend that new infections of the disease and its related death cases are high among these vulnerable groups. They thus call for due attention to avert gender disparity with a particular emphasis on adolescents and young women.

Although $65 \%$ of people living with HIV were on treatment in 2018, in 2019 , the proportion reduced to $62 \%$. Moreover, the proportion of HIV-infected pregnant women who received ARV dropped from $92 \%$ in 2018 to $74 \%$ in 2019. As a result, whiles 3700 new infections among new-born children were prevented in 2018, 3200 were prevented in 2019.

\section{Ghana}


In Ghana, the number of people living with HIV and the number of new cases increased in 2019 by $3 \%$ each from the numbers recorded in 2018 . However, the number of deaths decreased by about $4 \%$. Although HIV/AIDS deaths are higher among men than women and children, more women were living with the disease than men and children. Although HIV coverage was low in the country, it increased from $34 \%$ in 2018 to $45 \%$ in 2019. Moreover, the proportion of HIV-infected people who knew their status increased from $34 \%$ to $58 \%$. The reduction in the coverage of ARV among pregnant women from $79 \%$ in 2018 to $75 \%$ in 2019 , might have led to a reduction in the number of new infections among children from 4,056 to 2,500 for the same years. Thus, Ghana was at a great fallout from achieving the agenda 90-9090 .

\section{Zambia}

In Zambia, the number of people living with HIV increased by some $5 \%$ from the $1,200,000$ recorded in 2018 to 1,256,000 in 2019. Similarly, the number of new cases and deaths in 2019 increased by about $6 \%$ and $2 \%$ respectively from the numbers recorded in 2018. In of all these indicators, women were most hit. More than half of people who were living with the virus and deaths recorded were women. The disproportionate burden of HIV among women in Zambia has long been recognized. For instance, Campbell \& Kelly, (1995) indicated that women were at high risk for the virus due to several interrelated factors this including the economic, cultural, and educational status of women. Moreover, Nakazwe et al, (2019) contend that HIV is the leading cause of death among adults aged 15 years and older in Zambia.

Because of the high numbers of HIV infections and their related deaths in Zambia, prevention and treatment programs seem to have more attention. This is because the proportion of HIV-infected people who received ART increased from $78 \%$ in 2018 to $85 \%$ in 2019 . Also, $3 \%$ more people who had HIV knew their status than the proportion recorded in 2018. However, the proportion of HIV-infected pregnant who received treatment reduced from $95 \%$ in 2018 to $86 \%$ in 2019 . That notwithstanding, 9,100 infections among newborn babies were prevented in 2019 as compared with the 8,800 recorded in the previous year.

\section{Conclusion}

HIV/AIDS continues to pose threats to many lives in the Sub-Saharan Africa region. Women aged 15 years are the most hit on the continent. Although Zambia is a high hit country for the disease, impressive performances were made towards achieving the 2020 agenda 90-90-90. However, Ghana had a poor performance in testing as very few people who had the virus knew their status. In Ethiopia, more new cases were recorded among children than in men. ARV has been effective in reducing vertical transmission of the disease.

\section{Recommendations}

HIV prevention programs among countries in the Sub-Saharan Africa region should focus on women. Governments in the region and their development partners must bridge the gap between the social needs 
of men and women, to adequately empower women. Also, policies aimed at improving HIV testing among the general population and pregnant women are highly encouraged. Also, ARV services should be given serious attention as they are effective in preventing infections among newborn babies.

\section{Declarations}

\section{Acknowledgment}

We express our profound gratitude to Mr. Eric Acheampong for his immense contribution during the preparation of this manuscript.

\section{Authors Contribution}

Ebenezer conceived the idea. Ebenezer, Eliud, Eunice, and Kenneth gathered the materials needed for writing the manuscript. Ebenezer analyzed the data and drafted the report. Eliud, Eunice, and Kenneth contributed to the writing of the report to ensure its correctness and accuracy. Ebenezer, Eunice, Eliud, and Kenneth attested to the authenticity of the report and endorsed the same.

\section{Ethical Clearance}

$\mathrm{N} / \mathrm{A}$

The study did not require ethical clearance as no human subjects were involved.

\section{Funding}

No external funding was solicited for the conduct of this study.

\section{Conflict of interest}

The authors declare that there is no conflict of interest regarding the main research, authorship, and publication of this paper.

\section{Abbreviations}


AIDS Acquired Immune Deficiency Syndrome

\begin{tabular}{ll}
\hline ART & Antiretroviral Therapy \\
\hline HIV & Human Immune Virus \\
\hline MDG & Millennium Development Goals \\
\hline SDG & Sustainable Development Goals \\
\hline UNICEF & United Nations International Children's Emergency Fund \\
\hline WHO & World Health Organization
\end{tabular}

\section{References}

Avert. (2018). Global HIV Targets. Retrieved March 6, 2021, from Global information and education on HIV and AIDS website: https://www.avert.org/global-hiv-targets

Avert. (2020). Global HIV and AIDS Statistics. Retrieved March 6, 2021, from Global information and education on HIV and AIDS website: https://www.avert.org/global-hiv-and-aids-statistics

Awuba, J., \& Macassa, G. (2008). HIV/AIDS in Cameroon: Rising gender issues in policy-making matters. African Journal of Health Sciences, 14(3), 118-128. https://doi.org/10.4314/ajhs.v14i3.30857

Campbell, T., \& Kelly, M. (1995). Women and AIDS in Zambia: a review of the psychosocial factors implicated in the transmission of HIV. Pubmed, 7(3). https://doi.org/10.1080/09540129550126579

DCA. (n.d.). HIV/AIDS programme in Ethiopia. Retrieved March 8, 2021, from https://www.danchurchaid.org/articles/hiv-aids-programme-in-ethiopia\#: :text=DanChurchAid supports HIV\%2FAIDS prevention, people living with HIV\%2FAIDS.

Deribew, A., Biadgilign, S., Deribe, K., Dejene, T., Tessema, G. A., Melaku, Y. A., \& Lakew, Y. (2019). The Burden of HIV / AIDS in Ethiopia from 1990 to 2016: Evidence from the Global Burden of Diseases 2016 Study. Ethiop J Health Sci., 29(1), 2. Retrieved from https://www.ajol.info/index.php/ejhs/article/view/187188

Fowkes, F. J. I., Draper, B. L., Hellard, M., \& Stoové, M. (2016). Achieving development goals for HIV, tuberculosis and malaria in sub-Saharan Africa through integrated antenatal care: Barriers and challenges. BMC Medicine, 14(1), 1-10. https://doi.org/10.1186/s12916-016-0753-9

Ghana AIDS Commission. (2010). REPUBLIC OF GHANA NATIONAL HIV / AIDS STRATEGIC Table of Contents. 1-90.

Ghana AIDS Commission. (2019). Our Profile: About us. Retrieved March 10, 2021, from https://www.ghanaids.gov.gh/pages/about-us 
Girum, T., Wasie, A., Lentiro, K., Muktar, E., Shumbej, T., Difer, M., ... Worku, A. (2018). Gender disparity in epidemiological trend of HIV/AIDS infection and treatment in Ethiopia. Archives of Public Health, 76(1), 1-10. https://doi.org/10.1186/s13690-018-0299-8

Kharsany, A. B. M., \& Karim, Q. A. (2016). HIV Infection and AIDS in Sub-Saharan Africa: Current Status, Challenges and Opportunities. The Open AIDS Journal, 10(1), 34-48.

https://doi.org/10.2174/1874613601610010034

Kloos, H., \& Mariam, D. H. (2000). HIV/AIDS in Ethiopia: An Overview. Retrieved from jstor.org/stable/pdf/41931328.pdf?refreqid=excelsior\%3Ac2883df31442dd2da42d4ed77a24cb52

Mbanya, D., Sama, M., \& Tchounwou, P. (2008). Current Status of HIV/AIDS in Cameroon: How Effective are Control Strategies? International Journal of Environmental Research and Public Health, 5(5), 378383. Retrieved from chrome-extension://dagcmkpagjlhakfdhnbomgmjdpkdklff/enhanced-reader.html? openApp\&pdf=https\%3A\%2F\%2Fres.mdpi.com\%2Fd_attachment\%2Fijerph\%2Fijerph-0500378\%2Farticle_deploy\%2Fijerph-05-00378.pdf

Mirkuzie, A. H., Ali, S., Abate, E., Worku, A., \& Misganaw, A. (2021). Progress towards the 2020 fast track $\mathrm{HIV/AIDS}$ reduction targets across ages in Ethiopia as compared to neighboring countries using global burden of diseases 2017 data. BMC Public Health, 21(1), 1-10. https://doi.org/10.1186/s12889-021$10269-y$

Murray, C. J. L., \& et.al. (2014). Global, regional, and national incidence and mortality for HIV, tuberculosis, and malaria during 1990-2013: a systematic analysis for the Global Burden of Disease Study 2013. Lancet, 384: 1005- . Retrieved from https://doi.org/10.1016/S0140-6736(14)60844-8

Nakazwe, C., Michelo, C., Sandøy, I. F., \& Fylkesnes, K. (2019). Contrasting HIV prevalence trends among young women and men in Zambia in the past 12 years: Data from demographic and health surveys 20022014. BMC Infectious Diseases, 19(1), 1-9. https://doi.org/10.1186/s12879-019-4059-3

National Aids Council. (2014). ZAMBIA COUNTRY REPORT: Monitoring the Declaration of SUBMITTED TO THE UNITED NATIONS GENERAL ASSEMBLY. (January 2012), 1-72.

Pandey, A., \& Galvani, A. P. (2019). The global burden of HIV and prospects for control. The Lancet HIV, 6(12). Retrieved from https://www.thelancet.com/journals/lanhiv/article/PIIS2352-3018(19)302309/fulltext

Prendergast, A. J., Essajee, S., \& Penazzato, M. (2015). HIV and the millennium development goals. Archives of Disease in Childhood, 100(Suppl 1), S48-S52. https://doi.org/10.1136/archdischild-2013305548

Rawlings, H. E. F. L. J. J. (2001). Ghana HIV/AIDS Strategic Framework 2001-2005. Retrieved from https://www.ilo.org/wcmsp5/groups/public/--ed_protect/-protrav/-- 
ilo_aids/documents/legaldocument/wcms_126717.pdf

UNAIDS. (2020). 90-90-90: good progress, but the world is off-track for hitting the 2020 targets.

Retrieved March 10, 2021, from

https://www.unaids.org/en/resources/presscentre/featurestories/2020/september/20200921_90-90-

90\#: :text=AIDS committed cou-,In 2016\%2C the United Nations General Assembly's Political Declaration on,to undetectable levels $\% 2 \mathrm{C}$ so they

UNAIDS. (2021). UNAIDS welcomes the United Nations General Assembly decision to hold a high-level meeting on HIV and AIDS in 2021. Retrieved March 5, 2021, from SDGs website:

https://www.unaids.org/en/SDGs

UNICEF. (2020). UNICEF Cameroon Country Programme 2018-2020. 1-11. Retrieved from

http://files.unicef.org/transparency/documents/Strategy Note - Social Inclusion - final sd1.pdf

UNICEF Zambia. (n.d.). HIV/AIDS. Retrieved March 10, 2021, from

https://www.unicef.org/zambia/hivaids

USAID. (2020). President's emergency plan for AIDS relief (PEPFAR). Retrieved March 8, 2021, from https://www.usaid.gov/ethiopia/hivaids

WHO. (2005a). Country Profile: Zambia. Retrieved from https://www.who.int/hiv/HIVCP_ZMB.pdf

WHO. (2005b). Country Profile of Ethiopia. Retrieved from

https://www.who.int/3by5/support/june2005_eth.pdf

WHO. (2014). MDG 6: combat HIV/AIDS, malaria and other diseases. Retrieved March 6, 2021, from World Health Organinzation website: https://www.who.int/topics/millennium_development_goals/diseases/en/

WHO. (2020). HIV Disease Burden. Retrieved March 6, 2021, from World Health Organization website: https://www.afro.who.int/health-topics/hivaids\#: :text=The WHO African Region is,HIV in the African Region.

\section{Datasets}

\section{Cameroon}

https://www.unaids.org/en/regionscountries/countries/cameroon

http://unaids.mio.guru/en/regionscountries/countries/cameroon

\section{Ethiopia}

https://www.unaids.org/en/regionscountries/countries/ethiopia 
http://unaids.mio.guru/en/regionscountries/countries/ethiopia

\section{Ghana}

https://www.unaids.org/en/regionscountries/countries/ghana

https://ghanaids.gov.gh/mcadmin/Uploads/nationalHIVandAIDSPolicy.pdf

https://www.unaids.org/sites/default/files/country/documents/GHA_2019_countryreport.pdf

\section{Zambia}

https://www.unaids.org/en/regionscountries/countries/zambia

http://unaids.mio.guru/en/regionscountries/countries/zambia

\section{Figures}

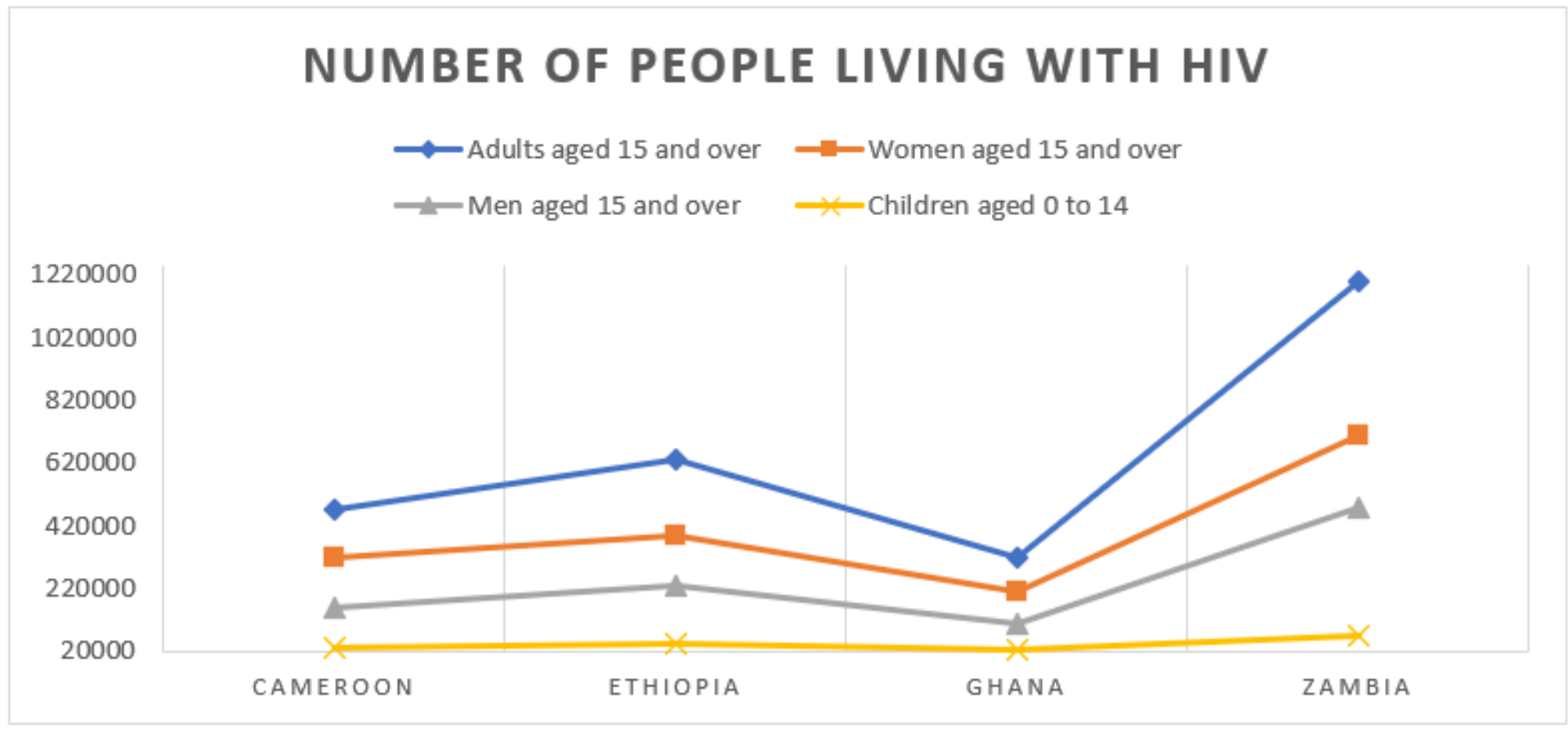

\section{Source: UNAIDS Country Factsheets (2019)}

\section{Figure 1}

Source: UNAIDS Country Factsheets (2019). In this figure, the number of people living with HIV in 2019 is presented. Cameroon: 31,000 children aged 0 to 14 years, 160,000 men aged 15 years and over, 320,000 women aged 15 and over, and 470,000 adults aged 15 and over. Ethiopia: 44,000 children aged 0 to 14 years, 230,000 men aged 15 years and over, 390,000 women aged 15 and over, and 630,000 adults aged 15 and over. Ghana: 26,000 children aged 0 to 14 years, 110,000 men aged 15 years and over, 210,000 women aged 15 and over, and 320,000 adults aged 15 and over. Zambia: 66,000 children aged 0 to 14 
years, 480,000 men aged 15 years and over, 710,000 women aged 15 and over, and 1,200,000 adults aged 15 and over.

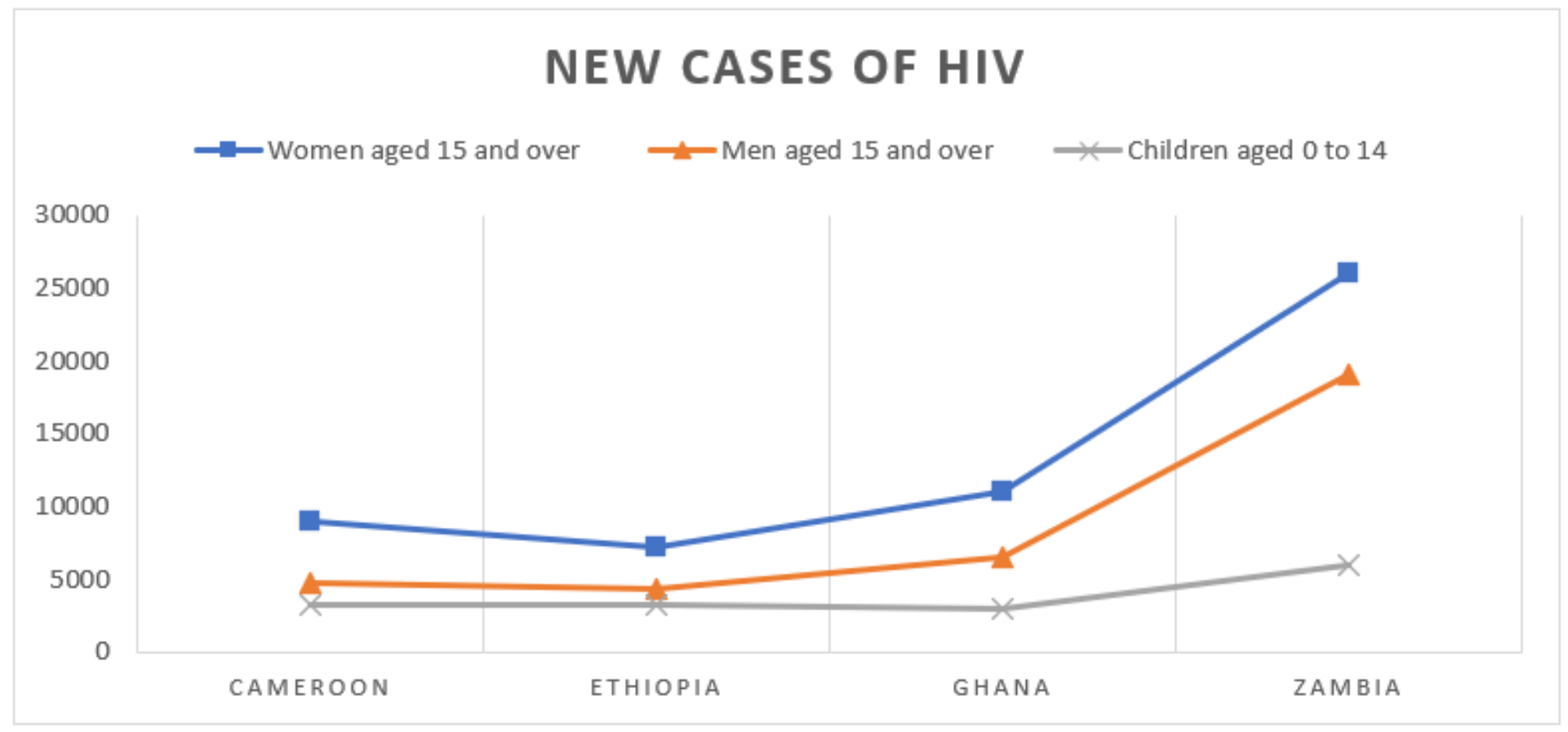

\section{Source: UNAIDS Country Factsheets (2019)}

\section{Figure 2}

Source: UNAIDS Country Factsheets (2019). In this figure, the number of new cases recorded in 2019 is presented. Cameroon: 3,300 children aged 0 to 14 years; 4,800 men aged 15 and over; 9,000 women aged 15 and over and 14,000. Ethiopia: 3,200 children aged 0 to $14 ; 4,400$ men aged 15 and over; 7,200 women aged 15 and over. Ghana: 3,000 children aged 0 to $14 ; 6,500$ men aged 15 and over; 11000 women aged 15 and over. Zambia: 6,000 children aged 0 to $14 ; 19,000$ men aged 15 and over and 26,000 women aged 15 and over. 


\section{DEATHS DUE TO AIDS}

$\longrightarrow$ Women aged 15 and over $\quad \leftarrow$ Men aged 15 and over $\quad \leftarrow$ Children aged 0 to 14

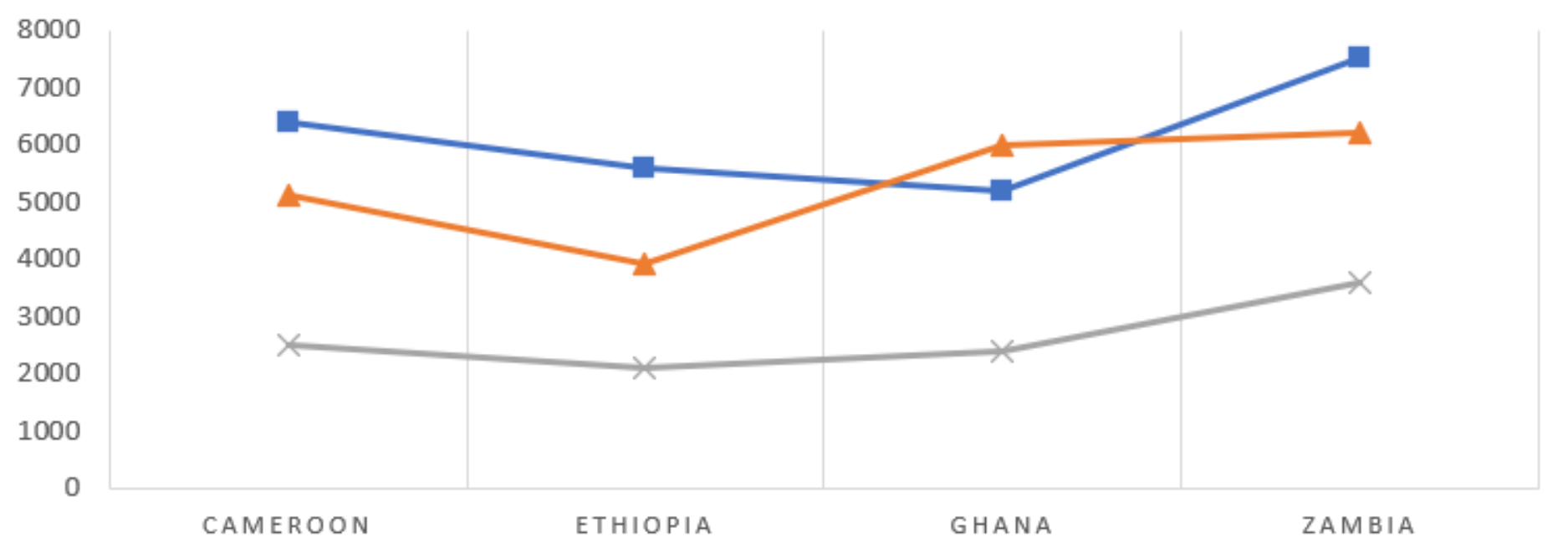

\section{Source: UNAIDS Country Factsheets (2019)}

\section{Figure 3}

Source: UNAIDS Country Factsheets (2019). This figure presents the number of deaths due to AIDS recorded in 2019. Cameroon: 2,500 children 0 to 14; 5,100 men aged 15 and over; 6,400 women aged 15 and over. Ethiopia: 2,100 children 0 to 14; 3,900 men aged 15 and over; 5,600 women aged 15 and over. Ghana: 2,400 children 0 to $14 ; 6,000$ men aged 15 and over; 5,200 women aged 15 and over. Zambia: 3,600 children 0 to $14 ; 6,200$ men aged 15 and over; 7,500 women aged 15 and over. 


\section{PERCENT OF PEOPLE LIVING WITH HIV WHO KNOW THEIR STATUS}

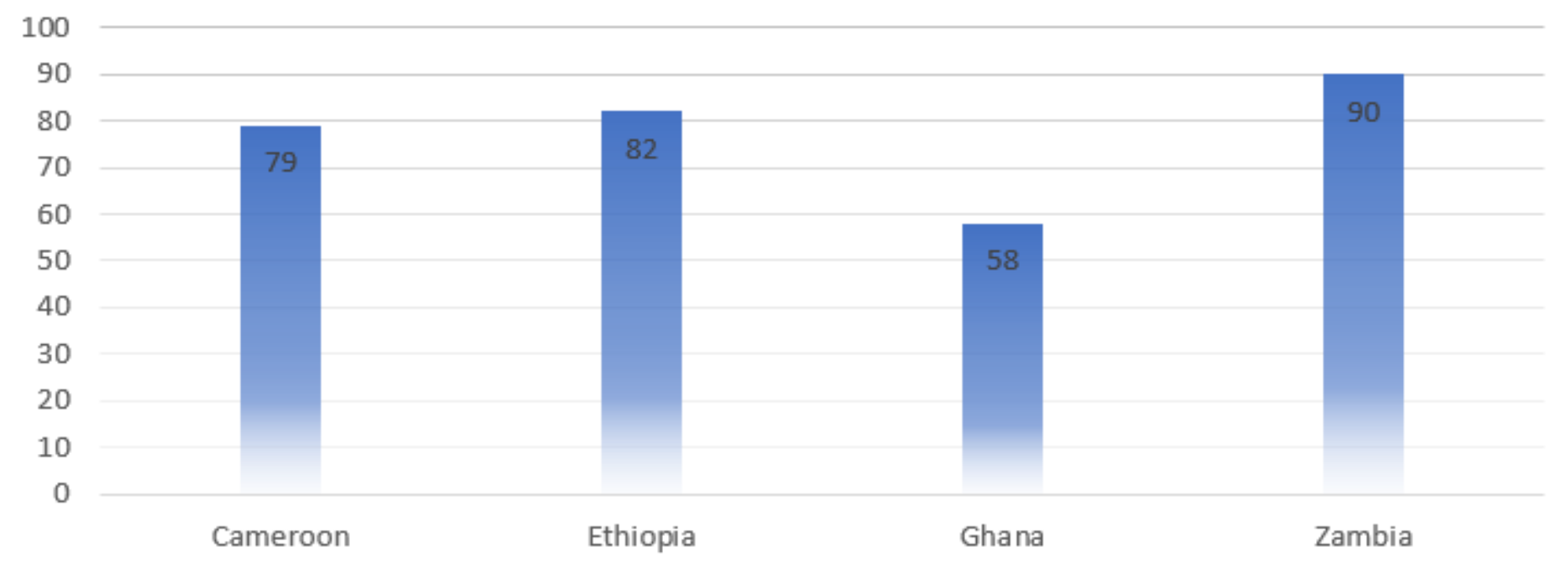

Source: UNAIDS Country Factsheets (2019)

\section{Figure 4}

Source: UNAIDS Country Factsheets (2019). The proportion of people who were living with HIV, and knew their status in 2019 are shown in the figure as Zambia (90\%), Ethiopia (82\%), Cameroon (79\%), and Ghana (58\%).

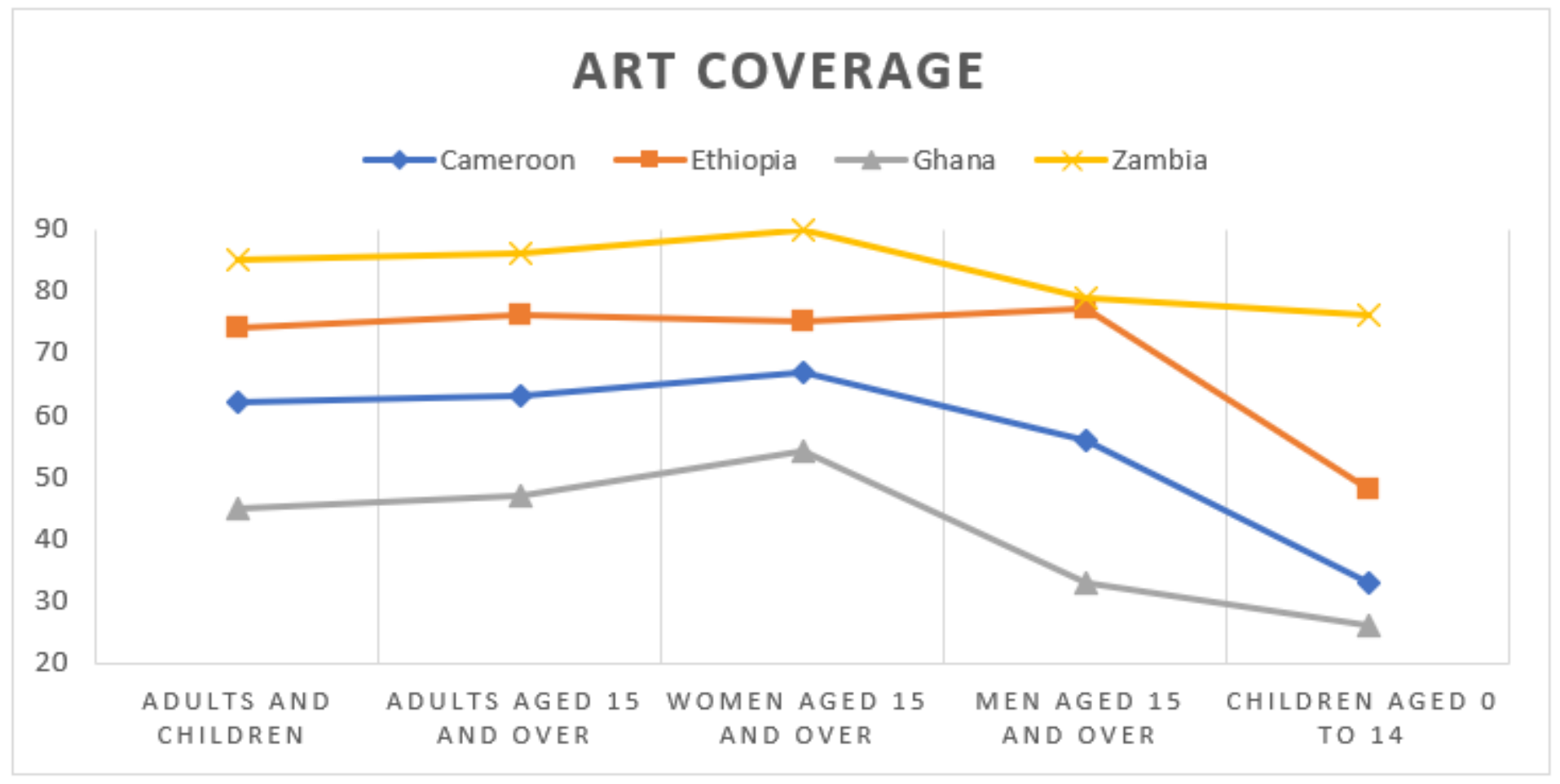

Source: UNAIDS Country Factsheets (2019) 


\section{Figure 5}

Source: UNAIDS Country Factsheets (2019). From this figure, ART Coverage among AIDS patients is presented. Cameroon: $62 \%$ among adults and children; $63 \%$ among adults aged 15 and over; $67 \%$ among women aged 15 and over; $56 \%$ among men aged 15 and over and 33\% among children aged 0 to 14 years. Ethiopia: $74 \%$ among adults and children; 76\% among adults aged 15 and over; $75 \%$ among women aged 15 and over; $77 \%$ among men aged 15 and over and $48 \%$ among children aged 0 to 14 years. Ghana: $45 \%$ among adults and children; $47 \%$ among adults aged 15 and over; $54 \%$ among women aged 15 and over; $33 \%$ among men aged 15 and over and $26 \%$ among children aged 0 to 14 years. Zambia: $85 \%$ among adults and children; $86 \%$ among adults aged 15 and over; $90 \%$ among women aged 15 and over; $79 \%$ among men aged 15 and over and $76 \%$ among children aged 0 to 14 years.

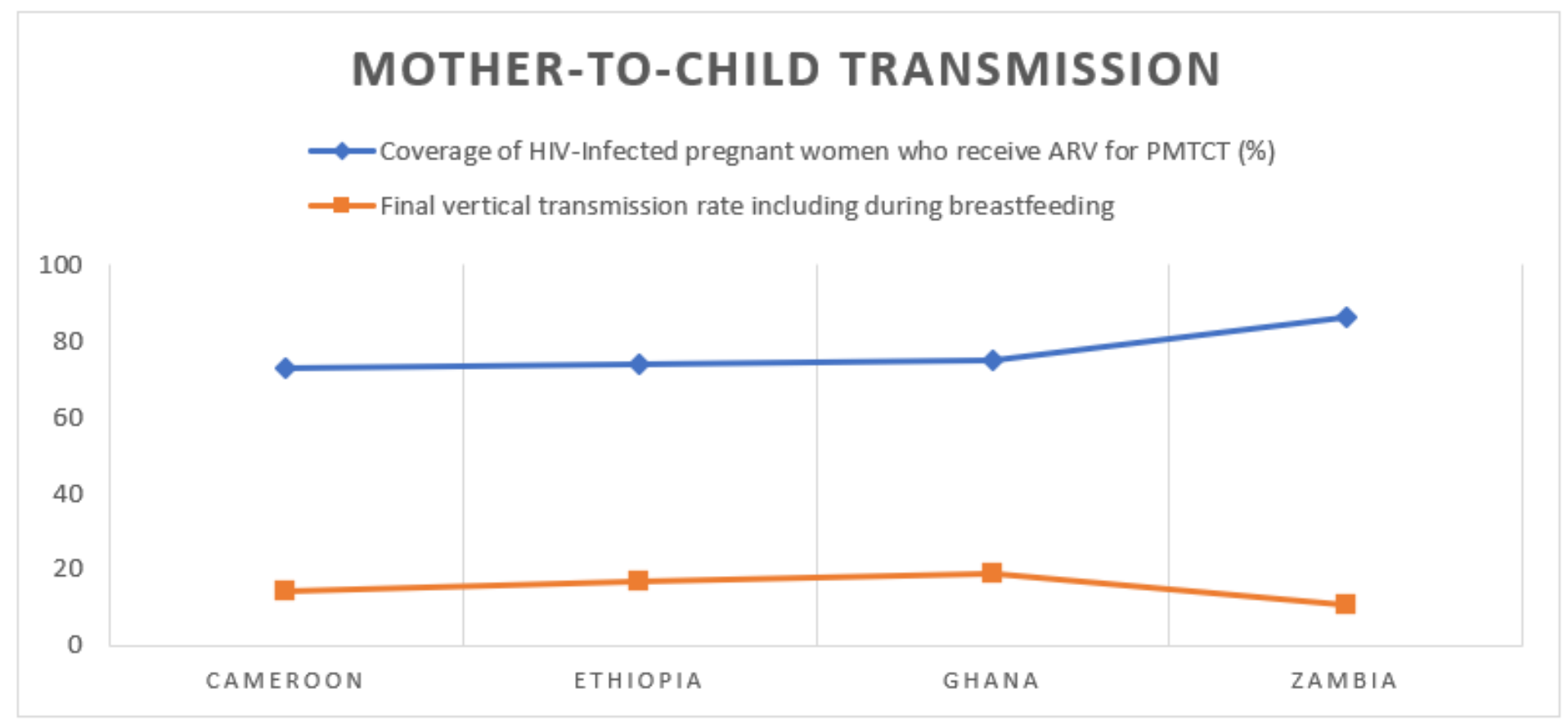

\section{Source: UNAIDS Country Factsheets (2019)}

\section{Figure 6}

Source: UNAIDS Country Factsheets (2019). From this figure, mother-to-child transmission of HIV is presented. With regards to the proportion of HIV-infected pregnant women who received ARV for PMTCT, Cameroon $73 \%$, Ethiopia $74 \%$, Ghana $75 \%$, and Zambia $86 \%$. With regards to the rate of vertical transmission. Cameroon 14.2\%, Ethiopia 16.9\%, Ghana 19\%, and Zambia 10.7\%. 